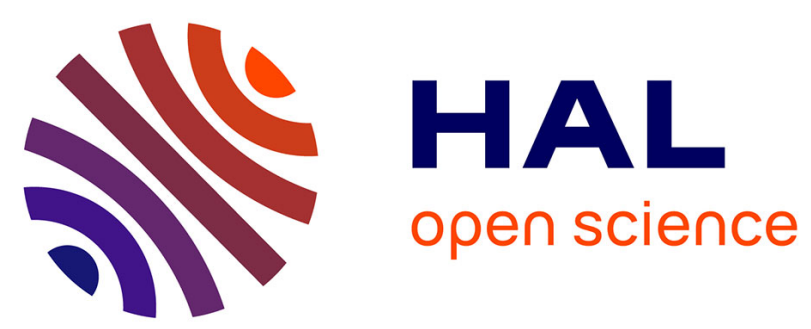

\title{
INVESTIGATION OF THE INFLUENCE OF DX CENTERS ON HEMT OPERATION AT ROOM TEMPERATURE
}

\author{
P. Godts, E. Constant, J. Zimmermann, D. Depreeuw
}

\section{- To cite this version:}

P. Godts, E. Constant, J. Zimmermann, D. Depreeuw. INVESTIGATION OF THE INFLUENCE OF DX CENTERS ON HEMT OPERATION AT ROOM TEMPERATURE. Journal de Physique Colloques, 1988, 49 (C4), pp.C4-705-C4-708. 10.1051/jphyscol:19884148 • jpa-00227886

\section{HAL Id: jpa-00227886 https://hal.science/jpa-00227886}

Submitted on 1 Jan 1988

HAL is a multi-disciplinary open access archive for the deposit and dissemination of scientific research documents, whether they are published or not. The documents may come from teaching and research institutions in France or abroad, or from public or private research centers.
L'archive ouverte pluridisciplinaire HAL, est destinée au dépôt et à la diffusion de documents scientifiques de niveau recherche, publiés ou non, émanant des établissements d'enseignement et de recherche français ou étrangers, des laboratoires publics ou privés. 


\title{
INVESTIGATION OF THE INFLUENCE OF DX CENTERS ON HEMT OPERATION AT ROOM TEMPERATURE
}

\author{
P. GODTS, E. CONSTANT, J. ZIMMERMANN and D. DEPREEUW \\ Centre Hyperfrequences et Semiconducteurs, CNRS-UA 287, Université des \\ Sciences et Techniques de Lille Flandres Artois, \\ F-59655 V1lleneuve-d'Ascq Cedex, France
}

RESIME - Une étude expérimentale et théorique des Centres DX dans les couches en AlGaAs est présentée. Il est montré qu'à cause des centres DX, à température ambiante, la transconductance hyperfréquence des HEMIs peut être cosidérablement plus élevée que celle obtenue en régime continu et approche les valeurs qui pourraient être obtenues si les centres DX n'existaient pas. En conséquence, pour des applications à température ambiante, des structures particulières destinées à éliminer les centres DX ne sont pas réellement nécessaires.

\begin{abstract}
ABSIRACI - A study of DX centers in GaAlAs layers is presented, both experimental and theoretical. It is shown that due to DX centers, at room temperature, the microwave transconductance of HEMTs can be considerably higher than that obtained from the DC regime, and approaches the values which could be expected if DX centers did not exist. As a result, for room temperature applications, special structures designed in order to eliminate DX centers are not really necessary.
\end{abstract}

It is now well known that, due to deep levels associated with DX centers in doped A $1_{x} \mathrm{Ga}_{1-x}$ As [1], the electrical properties of HEMTs may be strongly modified leading to low temperature collapse [2], persistent photoconductivity [3]. Solutions to this have been proposed : a reduction of Al mole fraction $x$ below 0.2; the use of a $n^{+}$GaAs-AlAs superlattice [4]; or even a planar (delta)-doped layer [5]. It is clear that these solutions are necessary for low temperature operation, but are they really useful for room temperature operation? Here, we study the effect of DX centers on DC and microwave properties of HEMTs at room temperature. We use a HEMT simulator which is able to take DX centers into account [6] and we will support our findings by a comparison with a few experimental data.

Dur theoretical study is carried out using a method which is somewhat similar to [6]. Since we are interested primarily in the influence of DX centers upon the drain current and device performance, we have to evaluate the importance of electron transfer between the GaAs and GaAlAs layers, requiring a correct evaluation of the gate current through the GaAlAs layer. To do this, we start with some 2 DEC density $n_{s}$ at some point of 
the source-drain channel, from which the exact position of the fermi level $E_{F}\left(n_{S}\right)$ with respect to the conduction band is known.

This $E_{F}\left(n_{s}\right)$ was established from exact results computed with a self-consistent solution of Schrödringer's equation [6]. Using this as the boundary condition for the solution of drift-diffusion and Poisson equations, the Fermi level through the AlGaAs layer is calculated and several assumptions for the effect of DX centers on the electron concentration can be compared. Then, at a given gate voltage, the gate current density can be computed once the correct boundary condition is met at the gate plane. This method is somewhat similar to the one presented by Ponse et al [7]. Thus, we get the $n_{s}$ and the total charge in the AlGaAs layer as a function of gate voltage. Finally, the drain current and gate-source capacitance are computed using a short channel approximation [8] by solving the following equations:

$$
\begin{aligned}
& I_{D S}=Z\left(Q_{s} \cdot v_{\text {CaAs }}+Q_{f r e e} \cdot v_{\text {GaAlAs }}\right) \\
& C_{g s}=Z \cdot L_{g} \cdot d\left(Q_{s}+Q_{f r e e}+Q_{D X}\right) / d v_{g s}
\end{aligned}
$$

where $Q_{S}=q \cdot n_{S}, Q_{f_{r e e}}$ is the free charge in the GaAlAs layer, and $Q_{D X}$ is the charge trapped on DX centers, $v_{\text {GaAs }}\left(v_{\mathrm{GaAlAs}}\right)$ is the peak drift velocity in GaAs (GaAlAs), $Z$ and Lg are respectively the gate length and the gate width.

The key-point here is in the way in which deep UX centers can be taken into account. We used some recent results reported by Theis [9] and made the following assumptions : i) every impurity atom gives rise to a deep donor level (presumably due to a oX center). ii) The deep donor level approximately follows the L-valley minimum as this latter changes with $x$ and is taken to be $140 \mathrm{meV}$ below the L-valley. iii) Shallow donor levels are not taken into account because at high doping concentrations used in HEMTs, the shallow impurity band is resonant with the $\Gamma$-valley. As a consequence, each impurity atom gives one electron which either can occupy a conduction band state or can be captured by a(positively) ionized empty deep donor level and the concentrations of these two types of occupied states can be determined since the quasi Fermi level is known.

In order to assess the role of DX centers, the main characteristics ( $g_{m}$, Cgs) of a typical HEMT structure have been computed both when DX centers, as described above, are taken into account or when they are ignored. This is illustrated in figure 1 . Dx centers have a strong influence on the transconductance at positive gate voltages. In DC regime a good part (depending on the Fermi level values) of electrons are trapped by Dx centers and this limits the upper values of the static drain current and consequently of $g_{m}$. When $o x$ centers are ignored, the $g_{m}$ can be substantially enhanced. Correspondingly, one finds that Cgs is also very sensitive to the effect of DX centers. Static regime can be characterized by times much longer than the emission or capture times on DX centers. Preliminary experiments performed in our laboratory showed that, at $300 \mathrm{~K}$, the capture time is of a few wS, although emission time is about 100 wS (see figure 2). Consequently, at SOOMHz and above,it can be assumed in our model that the charge trapped in DX centers depend on the static bias voltage $\mathrm{VgsO}$ and not on the microwave voltage $\triangle V_{g s}$. Taking into account these assumptions, the $Q_{S}, Q_{f_{r e e}}, Q_{D X}$ values can be determined for $V_{g s}=V_{g s} 0$ and then assuming no variation of the charge trapped in $D X$ centers for $V g s=V g s O+\Delta V g s$ (typical value 
used for $\Delta V_{g s}$ is 0.1 volt). By using such a method, the microwave $g_{m}$ including Dx centers can be computed and it is found ( $f$ igure 1) to be closer to the static $g_{m}$ when DX centers are neglected. Similar results are found for the gate capacitance.

In the rest of the paper we check this idea against experiments. We used two different methods in order to measure the static and microwave $g_{m}$ of HEMTs with a structure very similar to the one shown in figure 1. In the first method, a pulsed bias voltage is applied to the gate and the corresponding variation of the drain current is recorded (see figure 2 for an example). One then notes that the drain current observed just after the pulse has been applied, can be much higher than the drain current at longer times. This leads, for large positive value of the gate voltage, to microwave $g_{m} 30 \%$ higher than the static $g_{m}$. As a counter experiment we have checked that this behaviour is never observed in normal GaAs MESFETs where the effect of DX centers is negligable. A second method was also used to confirm these results : on one side the static $g_{m}$ is measured in the DC regime as a function of $V_{g s}$ and on the other side, the microwave $g_{m}$ is obtained from $S$ parameters measurements [10]. The results obtained in this way are presented in figure 3 . The fact that at $v_{g s}>0$ the microwave $g_{m}$ is substantially higher than the static $g_{m}$ is clearly seen. Moreover the results shown here are in quite good agreement with theoretical predictions of figure 1.

In conclusion, we have shown that, although the influence of the deep level due to DX centers in AlGaAs layers may be strong as concerns static characteristics, the influence on microwave performance is clearly much weaker. Consequently, at room temperature, special structures designed in order to eliminate DX centers formation in HEMTs appear not really necessary.
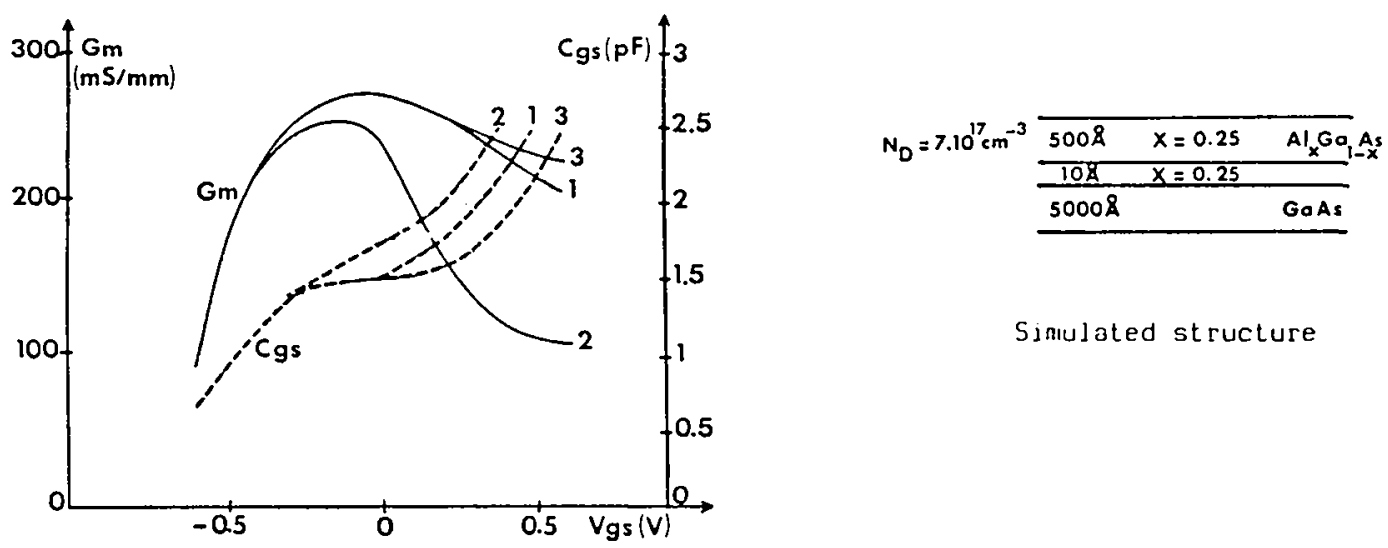

Sinulated structure

Figure 1 : This figure compares the computed results obtained (1) when DX centers are ignored; (2) when they are taken into account (see text) in DC regime; (3) when they are taken into account in the transient regime which characterizes DX centers behaviour at microwave frequency. 

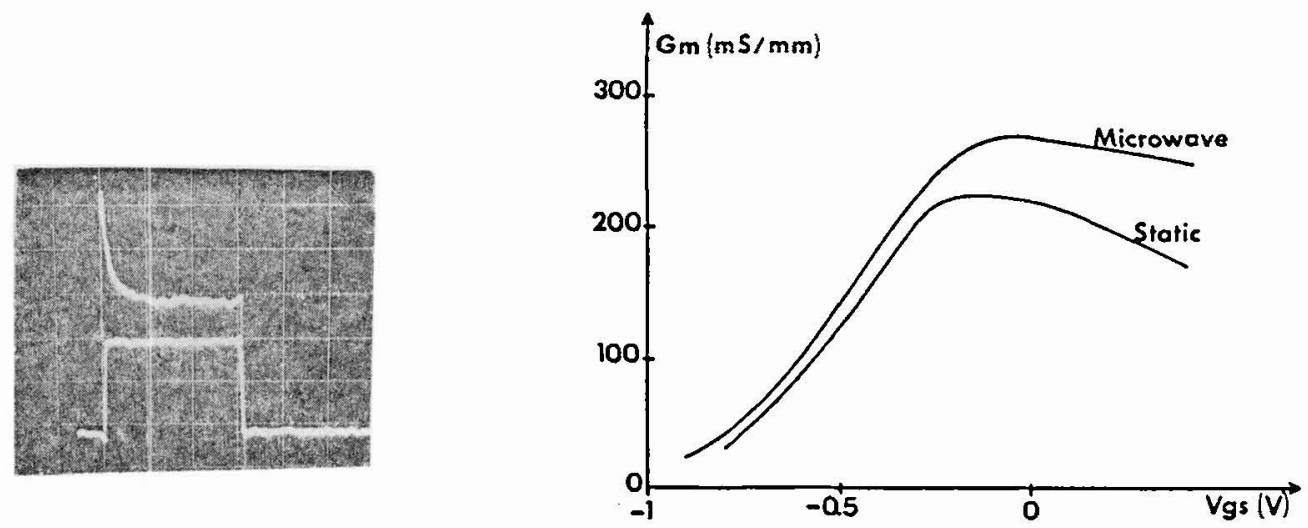

figure 2 :Drain current time response to a pulsed gate voltage. Shorter capture time by DX centers is observed at the beginning of the pulse and longer emission time is observed after extinction of the pulse.

Figure 3 :Experimental transconductance measured on a structure very similar to the one shown in fig.1. Static and microwave $(500 \mathrm{MHz})$ data are shown.

\section{REFERENCES}

[1] D.V.Lang, R.A.Logan and M.Jaros, Phys.Rev B., 19, 1015 (1979).

[2] J.F.Rochette, P.Delescluse, M.Laviron, D.Delagebeaudeuf, J.Chevrier and N.T.Linh, Inst.Physics Conf.Series., 65, 385 (1982).

[3] M.I.Nathan, Solid State Electron., 29, 167 (1986).

[4] W.Prost, W.Brockerhoff, K. Heime, W.Schlapp and G. Weimann, International Symp. on GaAs and Related Compounds, Heraklion (Crête), sept 1987.(Int. Physics Conf.Series., to appear).

[5] E.F.Schubert, A.Fischer and K.Ploog, IEEE Irans. Electron Dev., ED-33, 625 (1986).

[6] E.Constant, P.Godts, D.Depreeuw and J.Zimmermann, International Symp. on GaAs and Related Compounds, Heraklion (Crête), sept.1987 (Inst.Physics Conf.).

[7] F.Ponse, W.T.Masselink and H.Morkoç, IEEE Trans. Electron Dev., ED-32, 1017 (1985).

[8] A.Cappy, A.Vanoverschelde, M.Schortgen, C.Versnaeyen and G.Salmer, IEEE Trans.Electron.Dev., ED-32, 2787 (1985).

[9] T.N.Theis, International Symp. on GaAs and Related Compounds, Heraklion (Crête), sept. 1987 (Inst. Physics Conf.Series, to appear).

[10] G.Dambrine, A.Cappy, F.Heliodore, E.Playez, IEEE Trans. Microwave Theory and Techniques, to appear in July 1988. 